\title{
EFEITO DO SISTEMA DE CONDUÇ̃̃O EM ALGUMAS CARACTERÍSTICAS ECOFISIOLÓGICAS DA VIDEIRA (Vitis labrusca L.)"
}

\author{
Effect of the conduction system in some ecophysiological features of vine
}

\author{
Paulo Márcio Norberto ${ }^{2}$, Murillo de Albuquerque Regina ${ }^{3}$, Nilton Nagib Jorge Chalfun ${ }^{4}$, Angela Maria Soares ${ }^{5}$
}

\begin{abstract}
RESUMO
Os efeitos da interação entre a forma do dossel vegetativo e os fatores ambientais locais resultam no microclima que determinará alterações em alguns aspectos fisiológicos da videira, podendo afetar significativamente o crescimento vegetativo, a produtividade do vinhedo, bem como a qualidade da uva e do vinho. Objetivando-se avaliar o efeito do sistema de condução, sobre algumas características ecofisiológicas da videira (Vitis labrusca L.) foi desenvolvido experimento no Núcleo Tecnológico Epamig Uva e Vinho, na fazenda experimental "Retiro" no município de Caldas, MG, durante as safras 2003, 2004 e 2005. As variedades utilizadas no experimento foram Niágara Rosada para mesa e Folha de Figo, para produção de vinhos. Como porta - enxerto utilizou-se o "420A". O delineamento experimental foi inteiramente casualizado, em fatorial $4 \times 2$, e os sistemas de condução adotados foram: cordão simples, latada, espaldeira e lira. Determinaram-se as seguintes variáveis: superfície foliar exposta, potencial hídrico e trocas gasosas. Verificou-se que tanto o sistema espaldeira quanto o cordão simples conferiram a menor superfície foliar exposta, em ambas as variedades e os sistemas lira e latada os maiores valores de (SFE). Verificou-se também que os sistemas cordão simples e latada conferiram os maiores valores de potencial hídrico para as duas variedades, nas diferentes fases fenológicas. Em ambas as variedades e fases fenológicas estudadas, verificou-se um comportamento semelhante entre os tratamentos em que os resultados da taxa de assimilação fotossintética das folhas, não permite evidenciar o efeito dos sistemas de condução, sobre as trocas gasosas das plantas estudadas.
\end{abstract}

Termos para indexação: Uva, trocas gasosas, potencial hídrico, Vitis labrusca L.

\begin{abstract}
The effects of the interaction between the form of the canopy and the local environmental factors result in the microclimate that will determine some physiologic aspects of the grapevine, which could significantly affect the vegetative growth of the vine, the productivity of the vineyard, as well as the quality of the grape and wine. In this context, the present work was developed in the Station of Viticulture and Enology of Caldas EPAMIG, Caldas, MG. with the aim at evaluating the effect of the conduction system on the ecophysiological characteristics of the vine (Vitis labrusca L.) during the harvest of 2003, 2004, and 2005. 'Niágara Rosada' for table and 'Leaf of Fig' were the varieties used in the experiment for the wine production and 420-A was used as the rootstock. The experimental design was the DIC in factorial $4 \times 2$. The adopted conduction systems were simple string, trellis, "espaldeira", and "lira". The following variables were determined: exposed leaf surface; water potential; and gas exchange. It was verified that both the espaldeira system as well as the simple string provided the smallest leaf surface exposed in both varieties and the systems "lira" and trellis provided the largest values of (SFE). It was also verified that the simple string and trellis systems promoted the largest values of water potential for the two varieties, in the different phenological phases studied. In both varieties and phases a similar behavior was verified among the treatments in which the results of the photosynthetic assimilation rate of the leaves does not allow evidencing the effect of the conduction systems on the gas exchange of the studied plants.
\end{abstract}

Index terms: Grape, gas exchange, water potential, Vitis labrusca L.

(Recebido em 22 de fevereiro de 2007 e aprovado em 18 de abril de 2008)

\section{INTRODUÇÃO}

A videira não pode ser cultivada satisfatoriamente sem alguma forma de condução. Sendo planta sarmentosa, de hábito trepador, necessita de um sistema de suporte que garanta melhor exposição de suas folhas à luminosidade (REGINA et al., 1998).
Segundo Miele \& Mandelli (2005), o sistema de condução do vinhedo pode afetar significativamente o crescimento vegetativo da videira, a produtividade do vinhedo e a qualidade da uva e do vinho. Isso pode ocorrer em função do efeito do sistema de condução na parte aérea e subterrânea da videira. As características do sistema de

\footnotetext{
${ }^{1}$ Parte da tese de Doutorado do primeiro autor apresentada à Universidade Federal de Lavras/UFLA, Caixa Postal 37 - $37200-000$ - Lavras, MG 2Doutor - Br 494, Km 02 - 36301-360 - São João Del Rei, MG - paulonor@gmail.com

${ }^{3}$ Ph.D, Pesquisador - EPAMIG FECD - Cx. P. 33 - 37780-000 - Caldas, MG - murillo@epamigcaldas.br

${ }^{4}$ Doutor, Professor Titular - Departamento de Agricultura/DAG - Universidade Federal de Lavras/UFLA - Cx. P. 3037 - $37200-000$ - Lavras, MG nagib@ufla.br

${ }^{5}$ Doutora, Professora Adjunto - Departamento de Biologia/DBI - Universidade Federal de Lavras/UFLA - Cx. P. 3037 - $37200-000$ - Lavras, MG amsoares@ufla.br
} 
sustentação e de condução da videira podem aumentar a performance produtiva das plantas e qualitativa dos frutos, em maior ou menor escala, através do: a) aumento da área do dossel vegetativo através da divisão em cortinas; b) diminuição da densidade do dossel vegetativo, porque os ramos têm vigor mais fraco em função do maior número de gemas e porque há maior espaço entre os ramos; c) maior possibilidade para a mecanização da desponta, desfolha, colheita e poda de inverno; d) aumento da qualidade da uva e da produtividade da videira; e por último, pode melhorar a ação efetiva dos tratamentos fitossanitários, em função de dosséis vegetativos menos densos.

De todos os recursos de que as plantas precisam para o crescimento, a água é o mais limitante para a produtividade agrícola, visto ser essencial aos diversos processos metabólicos, principalmente durante o período inicial de desenvolvimento. Uma das primeiras respostas das plantas à deficiência hídrica, é o fechamento dos estômatos, e com isto, a diminuição da difusão de $\mathrm{CO}_{2}$ para o mesofilo foliar, o que causa a queda na fotossíntese (SOUSA et al., 2001).

Orlando et al. (2003), relatam que, na região sul de Minas Gerais, as condições climáticas na época de maturação da uva não são adequadas, especialmente devido à alta precipitação e elevada nebulosidade, reduzindo assim a qualidade da uva e por consequiência, a do vinho. Em estudo realizado nesta região com videiras 'Folha de Figo' e Niagara Rosada', cultivadas em diferentes sistemas de condução, Norberto et al. (2008) observaram diferenças na produção e qualidade dos frutos associadas ao sistema de condução. Portanto, acredita-se que, com o uso correto do sistema de condução, pode-se minimizar os efeitos negativos do excesso de chuvas e nebulosidade sobre a qualidade da uva, por propiciar condições microclimáticas mais favoráveis às trocas gasosas e, assim, melhorar a qualidade do produto final. Por essa razão, objetivou-se, no presente trabalho, avaliar o efeito de diferentes sistemas de condução, sobre algumas características ecofisiológicas das videiras Folha de Figo e Niágara Rosada (Vitis labrusca L.), em diferentes fases fenológicas.

A taxa fotossintética é influenciada por diversos fatores climáticos e por aqueles ligados internamente à planta. Entre os fatores climáticos que interferem preponderantemente na transformação de $\mathrm{CO}_{2}$ em açúcar, destaca-se luz e temperatura. Esses dois fatores podem ser modificados drasticamente pelo sistema de condução, contribuindo assim para elevar a capacidade fotossintética das videiras (KLIEWER et al., 2000; PERUZZO, 1990; REGINA \& CARBONNEAU, 1998).

A captação da energia luminosa é feita de forma diferenciada em razão das características inerentes a cada sistema de condução da videira. A penetração da radiação solar no dossel vegetativo favorece a iniciação floral, a fertilidade da gema, o pegamento do fruto e maturação da uva (CARBONNEAU, 1982). Além disso, influencia o desenvolvimento da planta e a síntese de açúcar (GRIBAUDO et al., 1988), melhorando a produção e a qualidade da uva (SMART, 1985).

\section{MATERIALE MÉTODOS}

O trabalho foi realizado no Núcleo Tecnológico Epamig Uva e Vinho, na fazenda experimental "Retiro", no município de Caldas, MG, durante as safras 2003, 2004 e 2005. Caldas apresenta temperatura anual média de $19^{\circ} \mathrm{C}$, umidade relativa média anual de $75 \%$ e precipitação pluviométrica anual de $1500 \mathrm{~mm}$. As variedades copa utilizadas no experimento foram Niágara Rosada e Folha de Figo, enxertadas no porta - enxerto o 420-A, oriundas da coleção de variedades da Epamig. Os tratamentos foram constituídos de quatro sistemas de condução: espaldeira, latada, lira e cordão simples. O delineamento experimental adotado foi inteiramente casualizado, com quatro repetições de quatro plantas por parcela, perfazendo um total de 64 plantas. As plantas foram distribuídas no campo, obedecendo aos espaçamentos de 2,5 m entre linhas e 1,5 $\mathrm{m}$ entre plantas no sistema em espaldeira, 2,5 m entre linhas e 2,0 m entre plantas na latada, 2,5 m entre linhas e 3,5 m entre plantas no cordão simples e 3,5 m em linhas e $1,0 \mathrm{~m}$ entre plantas em lira.

Características avaliadas nas safras 2003, 2004 e 2005:

\section{Superfície foliar exposta (SFE):}

Foi medida durante as safras 2004 e 2005, nas fases fenológicas de final de floração e pré-colheita. Os dados apresentados são médios, esse parâmetro, serve como índice sintético que permite estimar o potencial qualitativo do sistema de condução adotado. A metodologia foi descrita por Carbonneau (1989).

\section{Potencial hídrico:}

Foi determinado em diferentes fases fenológicas, com características climáticas distintas, nas duas variedades em cada uma das três safras avaliadas. Utilizouse bomba de pressão, tipo Scholander et al. (1965). O potencial hídrico de base foi medido no escuro antes que os primeiros raios solares da manhã aparecessem e a planta começasse a realizar fotossíntese. Essa medida foi tomada em quatro folhas por sistema, posicionadas logo acima do primeiro cacho no ramo.

\section{Trocas gasosas:}

Foram medidas nas safras 2003, 2004 e 2005 em ambas fases fenológicas e variedades. Utilizou-se um analisador portátil de $\mathrm{CO}_{2}$ por infravermelho (IRGA), modelo CID- 
301PS. Avaliou-se a fotossíntese líquida (A), condutância estomática (gs), densidade de fluxo de fótons fotossinteticamente ativos (DFFFA), umidade relativa (UR), temperatura de folha, temperatura e umidade relativa da câmara, determinando-se os valores do déficit de pressão de vapor da atmosfera (DPV). Utilizaram-se folhas adultas, sadias e expostas à radiação solar máxima, no terço mediano do dossel vegetativo, no horário das $10 \mathrm{~h}$ (hora solar).

\section{RESULTADOS E DISCUSSÃO}

\section{Superfície foliar exposta (SFE)}

Os dados de superfície foliar exposta médios apresentaram comportamento semelhante para as duas variedades em estudo em ambas as fases fenológicas, (Tabela 1) e (Figuras 1 e 2), em que verifica-se que o sistema latada conferiu os maiores valores de (SFE), com $1,09 \mathrm{~m}^{2}$, na variedade Folha de Figo e 1,23 $\mathrm{m}^{2}$ na variedade Niágara Rosada, porém sem diferir da lira com $1,02 \mathrm{~m}^{2} \mathrm{e}$ $1,12 \mathrm{~m}^{2}$ respectivamente. Todavia os menores valores de (SFE), foram verificados nos sistemas espaldeira e cordão simples para as duas variedades, Uma possível explicação para o resultado verificado é que o sistema de condução latada, apesar de conferir sempre os maiores valores de superfície foliar, sua camada vegetal não foi demasiadamente densa, em razão do baixo vigor do conjunto copa/porta - enxerto empregado, resultando em poucas camadas foliares, o que pode ter contribuído para uma maior superfície foliar exposta. Confirmando essa hipótese Chaves (1986), relata que o acréscimo de índice de área foliar (IAF), não é necessariamente compensado pelo aumento da atividade fotossintética global, devido à deficiente penetração de luz causada por valores excessivos de (IAF).

\section{Potencial hídrico foliar $(\psi \mathrm{w})$}

Tanto os resultados médios do potencial hídrico de base (Tabela 2), quanto nas safras 2003, 2004 e 2005, em separado, em ambas as fases fenológicas e variedades estudadas, (Figuras 1 e 2), confirmam-se que os sistemas lira e espaldeira propiciaram os menores valores de potencial, e o sistema cordão simples, os maiores. Esses resultados estão de acordo com os obtidos por (ORLANDO, 2002), que também verificou que os sistemas espaldeira e lira foram os sistemas que imprimiram os menores valores de potencial hídrico de base. Outra hipótese que talvez explique o resultado verificado, é que nos sistemas de porte mais baixo, ou seja, com a cepa mais próxima ao solo, como é o caso da espaldeira e da lira, diminui-se a distância física entre o gradiente de umidade do solo e do dossel vegetativo das plantas. Chaves (1986) relata que a altura do tronco condiciona a altura do dossel vegetativo, e influencia o estado hídrico da planta, devido à renovação mais freqüente de ar dentro das camadas de folhas mais altas, que é chamado de demanda evaporativa da planta, provocando uma diminuição da umidade relativa próxima às folhas, aumentando a transpiração, portanto, inferindo um menor valor de potencial hídrico.

Tabela 1 - Superfície foliar exposta (SFE) média, das variedades Folha de Figo e Niágara Rosada, conduzidas sob diferentes sistemas de condução na safra 2004, 2005. EPAMIG, Caldas-MG, 2005.

\begin{tabular}{lcc}
\hline $\begin{array}{c}\text { Sistema de } \\
\text { condução }\end{array}$ & Folha de Figo & Niágara Rosada \\
\cline { 2 - 3 } & SFE $\left(\mathrm{m}^{2}\right)$ & SFE $\left(\mathrm{m}^{2}\right)$ \\
\hline & $\begin{array}{c}\text { Dados Médios } \\
\text { Safra 2004 e 2005 }\end{array}$ \\
\hline Espaldeira & $0,74 \mathrm{~b}$ & $0,82 \mathrm{c}$ \\
Cordão & $0,80 \mathrm{~b}$ & $0,89 \mathrm{c}$ \\
Simples & $1,02 \mathrm{a}$ & $1,12 \mathrm{~b}$ \\
Lira & $1,09 \mathrm{a}$ & $1,23 \mathrm{a}$ \\
Latada & &
\end{tabular}

*Médias seguidas pela mesma letra na coluna não diferem estatisticamente entre si pelo teste de Scott-Knott, ao nível de $5 \%$ de probabilidade.

Tabela 2 - Potencial hídrico foliar de base, dados médios das variedades Folha de Figo e Niágara Rosada, em ambas as fases fenológicas, conduzidas sob diferentes sistemas de condução, EPAMIG, Caldas-MG, 2005.

\begin{tabular}{|c|c|c|}
\hline \multicolumn{3}{|c|}{$\begin{array}{l}\text { Potencial hídrico Foliar (MPa) de base } \\
\text { (final de floração) }\end{array}$} \\
\hline $\begin{array}{l}\text { Sistema de } \\
\text { Condução }\end{array}$ & Folha de figo & Niágara Rosada \\
\hline Espaldeira & $-1,64 \quad \mathrm{a}$ & $-1,66 \quad a$ \\
\hline Lira & $-1,61 \quad a$ & $-1,64 \quad a$ \\
\hline Latada & $-1,86 \quad b$ & $-1,89 b$ \\
\hline Cordão Simples & $-1,79$ & $-1,78 \quad b$ \\
\hline \multicolumn{3}{|c|}{ Potencial hídrico Foliar (MPa) de base (pré-colheita) } \\
\hline $\begin{array}{l}\text { Sistema de } \\
\text { Condução }\end{array}$ & Folha de figo & Niágara Rosada \\
\hline Espaldeira & $-0,85 \quad a$ & $-0,59 \quad a$ \\
\hline Lira & $-0,78 \quad a$ & $-0,55 \quad a$ \\
\hline Latada & $-1,01 \quad b$ & $-0,90 \quad b$ \\
\hline Cordão Simples & $-1,22 \quad b$ & $-1,21 \quad c$ \\
\hline
\end{tabular}

*Médias seguidas pela mesma letra na coluna não diferem estatisticamente entre si pelo teste de Scott-Knott, ao nível de $5 \%$ de probabilidade. 


\section{Trocas gasosas}

A avaliação das três safras no horário das 10:00 h, em ambas as fases fenológicas, para variedade Folha de figo (Figura 1) e 'Niagara Rosada' (Figura 2), mostrou-se mais sensível à observação de tendências entre os tratamentos. Portanto a uniformidade de respostas entre os sistemas de condução é clara e se explica devido à igualdade das condições ambientais, com ausência de limitações meteorológicas às trocas gasosas, o que contribui, para que, no momento das medidas de DPV e DFFFA, não fossem verificadas diferenças em termos de taxa fotossintética líquida, entre os sistemas em um mesmo horário, uma vez que as medidas foram realizadas sempre em folhas totalmente expostas à radiação solar. Indicando que talvez não houvesse restrições carboxilativas da planta, impostas pelos sistemas de condução, desde que o microclima não seja limitante, para os processos fisiológicos da videira. Assim, os resultados das trocas gasosas, no horário das 10:00 h para a variedade Folha de Figo, quando se consideram as duas fases fenológicas conjuntamente, embora demonstrem alguma tendência específica para alguma variável, em uma determinada safra, a uniformidade de respostas dos sistemas de condução às trocas gasosas é notória e não significativa entre os tratamentos. Em geral, os resultados verificados para essa variedade são semelhantes aos verificados para 'Niagara



Figura 1 - Potencial hídrico $(\psi \mathrm{w})$, densidade de fluxo de fótons fotossintéticamente ativos (DFFFA), déficit de pressão de vapor (DPV), fotossíntese líquida (A), condutância estomática (gs), observados no horário das 10 horas, na variedade Folha de Figo, nas duas fases fenológicas sob diferentes sistemas de condução, dados médios das safras 2003 , 2004 e 2005, e superfície foliar exposta (SFE), dados médios das safras 2004 e 2005, EPAMIG, Caldas-MG, 2005. 
Rosada' que também apresentou apenas discretas tendências de comportamento dos sistemas de condução em relação às trocas gasosas, por exemplo, por não haver diferenças significativas de gs, não houve restrição estomática para a carboxilação, e os menores valores de DPV podem estar associados aos maiores valores de gs, o que provavelmente permitiu uma maior fotossíntese (A) para os mesmos níveis de DFFFA. Esse comportamento está de acordo com os resultados verificados por Regina \& Carbonneau (1999), que observaram o comportamento das cultivares Chardonnay, Semillon e Cabernet-Sauvignon em condições de campo, onde os valores de fotossíntese são próximos um do outro, quando todas as condições de crescimento e desenvolvimento das plantas não oferecem qualquer tipo de limitação.

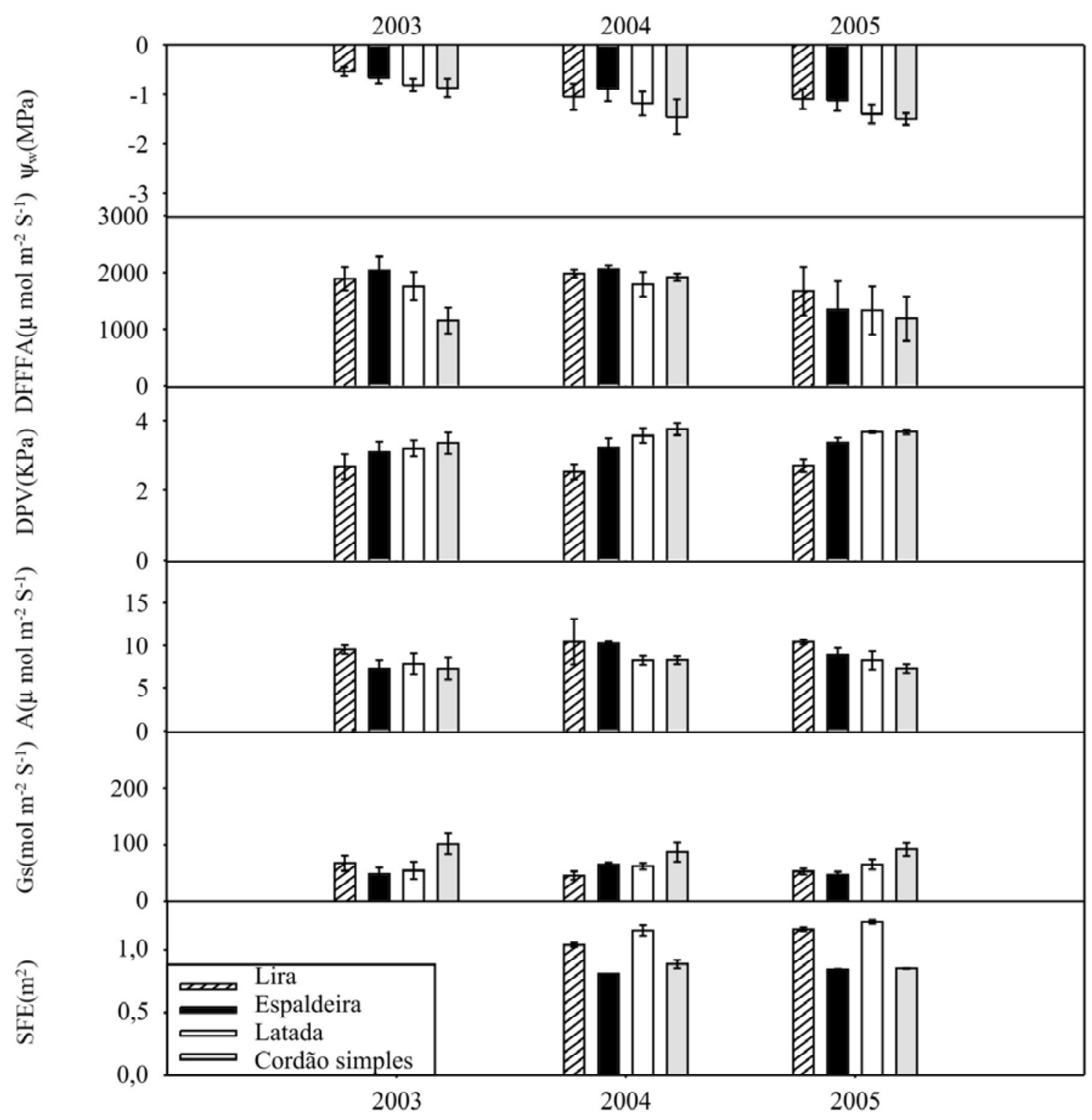

Figura 2 - Potencial hídrico $(\psi$ w), densidade de fluxo de fótons fotossintéticamente ativos (DFFFA), déficit de pressão de vapor (DPV), fotossíntese líquida (A), condutância estomática (gs), observados no horário das 10 horas, na variedade Niágara Rosada, nas duas fases fenológicas sob diferentes sistemas de condução, dados médios das safras 2003, 2004 e 2005, e superfície foliar exposta (SFE), dados médios das safras 2004 e 2005. EPAMIG, Caldas-MG, 2005. 


\section{CONCLUSÕES}

O sistema cordão simples confere menor superfície foliar total, em ambas as variedades.

A superfície foliar exposta (SFE), é superior, nos sistemas de condução latada e lira.

Sistemas de condução de troncos altos, induzem maiores valores de potencial hídrico de base.

A taxa de assimilação fotossintética das folhas, não permitiu diferenciar o efeito dos sistemas de condução.

\section{REFERÊNCIAS BIBLIOGRAFICAS}

CARBONNEAU, A. Apports biologiques récents à l'étude des systèmes de conduite. Bulletin de l'O. I. V., Paris, v. 55, n. 614, p. 273-285, 1982.

CARBONNEAU, A. Interet et codification du systeme de conduite em double palissage-lyre. Compte Rendu, Bordeaux, v. 4, p. 202-214, 1989.

CHAVES, M. M. Fotossíntese e repartição dos produtos de assimilação em Vitis vinifera L. 1986. 220 f. Tese (Doutorado) - Universidade Técnica de Lisboa, Lisboa, 1986.

GRIBAUDO, I.; SCHUBERT, A.; NOVELLO, V. Produzione di sostanza secca ed intercettazione di energia luminosa nel vitigno "Cortese" in quattro forme di allevamento. Vignevini, Bologna, v. 15, n. 3, p. 53-56, 1988.

KLIEWER, W. M.; WOLPET, J. A.; BENZ, M. Trellis and vine spacing effects on growth, canopy microclimate, yield and fruit composition of Cabernet Sauvignon. Acta Horticulturae, Wageningen, v. 526, p. 21-31, 2000.

MIELI, A.; MANDELLI, F. Sistemas de condução da videira. Brasília, DF: Embrapa Uva e Vinho, 2005.

ORLANDO, T. G. S. Características ecofisiológicas de cultivares de videira em diferentes sistemas de condução. 2002. 126 p. Tese (Doutorado em Fitotecnia) Universidade Federal de Lavras, Lavras, 2002.
NORBERTO, P. M.; REGINA, M. DE A.; CHALFUN, N. N. J.; SOARES, A.M.; FERNANDES, V. B. Influência do sistema de condução na produção e na qualidade dos frutos das videiras folha de figo e niagara rosada em Caldas, MG. Ciência e Agrotecnologia. Lavras, v. 32, n. 2, p. 450-455, mar./abr., 2008.

ORLANDO, T. G. S.; REGINA, M. A.; SOARES, A. M.; CHALFUN, N. N. J.; SOUZA, C. M.; FREITAS, G. F.; TOYOTA, M. Caracterização agronômica de cultivares de videira (vitis labrusca 1.) em diferentes sistemas de condução. Ciência e Agrotecnologia, Lavras, p. 14601469, dez. 2003. Edição especial.

PERUZZO, E. L. Efeitos do sombreamento e da área foliar na produção e qualidade do fruto de Vitis labrusca L., c. v “Niagara Rosada”. 1990. 69 f. Dissertação (Mestrado em Fisiologia Vegetal) - Universidade Federal de Viçosa, Viçosa, 1990.

REGINA, M. de A.; CARBONNEAU, A. trocas gasosas em videira sob regime de estresse hídrico: II fotorrespiração e comportamento varietal. Pesquisa Agropecuária Brasileira, Brasília, v. 34, n. 1, p. 37-43, jan. 1999.

REGINA, M. de A.; PEREIRA, A. F.; ALVARENGA, A. A.; ANTUNES, L. E. C.; ABRAHÃO, E. Sistema de condução da videira. Informe Agropecuário, Belo Horizonte, v. 19, n. 194, p. 5-8, set. 1998.

SCHOLANDER, P. F.; HAMMEL, H. T.; BRADSTREET, E. D.; HEMMINGEN, A. E. Sap pressure in vascular plants. Science, v. 148, p. 339-346, 1965.

SMART, R. E. Principles of grapevine canopy microclimate manipulation with implications for yield and quality: a review. American Journal of Enology and Viticulture, Davis, v. 36, n. 3, p. 230-239, 1985.

SOUZA, C. R.; SOARES, A. M.; REGINA, M. de A. Trocas gasosas de mudas de videira, obtidas por dois porta-enxertos, submetidas à deficiência hídrica.

Pesquisa Agropecuária Brasileira, Brasília, v. 36, n. 10, p. 1221-1230, out. 2001. 